\title{
Earthquake recurrence and seismic hazard assessment: a comparative analysis over the Italian territory
}

\author{
A. Peresan ${ }^{1,2}$, A. Magrin ${ }^{1,}$, A. Nekrasova ${ }^{2,3}$, V. G. Kossobokov ${ }^{3,4}$ \\ \& G. F. Panza ${ }^{1,2,5}$ \\ ${ }^{1}$ Department of Mathematics and Geosciences, University of Trieste, Italy \\ ${ }^{2}$ The Abdus Salam International Centre for Theoretical Physics, \\ SAND Group, Trieste, Italy \\ ${ }^{3}$ IIEPT, Russian Academy of Sciences, Moscow, Russian Federation \\ ${ }^{4}$ Institut de Physique du Globe de Paris, France \\ ${ }^{5}$ Institute of Geophysics, China Earthquake Administration, \\ Beijing, China
}

\begin{abstract}
Rigorous and objective testing of seismic hazard assessments against real seismic activity are a necessary precondition for any responsible seismic risk assessment. The reference hazard maps for the Italian seismic code, obtained with the classical probabilistic approach (PSHA) and the alternative ground shaking maps based on the neo-deterministic approach (NDSHA) are crosscompared and tested against the real seismicity for the territory of Italy. NDSHA is a methodology that allows for the sound definition of credible scenario events, based on the realistic physical modelling of ground motion from a wide set of possible earthquakes. The flexibility of NDSHA permits to account for earthquake recurrence and allows for the generation of ground motion maps at specified return periods that permits a straightforward comparison between the NDSHA and the PSHA maps.
\end{abstract}

Keywords: seismic hazard, neo-deterministic method, recurrence, probabilistic method. 


\section{Introduction}

Rigorous and objective testing of seismic hazard estimates against the real seismic activity are a necessary precondition for any responsible seismic risk assessment. Recent analysis showed that the performances of the traditional probabilistic approaches to seismic hazard assessment (PSHA) in predicting ground shaking are very unsatisfactory.

A viable alternative to the probabilistic method is represented by the sound definition of credible scenario events by the neo-deterministic approach (NDSHA) (Panza et al. [2]), a methodology based on the realistic modelling of ground motion, which permits the generalization of empirical observations by means of physically sound theoretical considerations. The NDSHA approach allows for a realistic description, at any point of interest, of the seismic ground motion due to an earthquake of given distance and magnitude. From the computed complete synthetic seismograms the estimates of peak ground acceleration, velocity and displacement, or any other parameter relevant to seismic engineering, can be extracted. The NDSHA approach has been quit widely applied in several countries, including Italy (Panza et al. [3]).

NDSHA, in its standard form, defines the hazard as the maximum ground shaking at the site, computed considering a large set of scenario earthquakes, including the maximum credible earthquake (MCE); hence it does not supply information about the frequency of occurrence of the expected ground shaking.

We show here that the flexibility of NDSHA permits to account for earthquake recurrence and eventually allows for the generation of ground shaking maps at specified return periods. The characterization of the frequencymagnitude relation for earthquakes in the Italian region is performed according to the multi-scale seismicity model $[4,5]$ and a recurrence estimate is associated to each of the modelled sources. Since the frequency of the source is associated to the related seismograms, a standard map of ground shaking is obtained along with the map of the corresponding recurrence. The introduction of recurrence estimates in NDSHA allows the natural generation of ground shaking maps for specified return periods that permits a straightforward comparison between the NDSHA and the PSHA maps.

The reference hazard maps for the Italian seismic code, obtained by PSHA, and the alternative ground motion maps based on NDSHA are cross-compared and tested against the real seismicity for the territory of Italy (for details see Nekrasova et al. [6]). The comparative analysis evidences the very severe dependency of PSHA expected ground shaking on earthquakes recurrence (i.e. on the probability threshold selected for the maps), which is affected by large uncertainties and often turns out incorrect. The comparison between predicted intensities and those reported for past earthquakes shows that the predictions, as a rule, provide rather conservative estimates, except for PGA with $10 \%$ probability of being exceeded in 50 years, which underestimates the largest earthquakes. The comparison shows that the maps estimated for a fixed probability of exceedance, strongly depend on the corresponding return period, with NDSHA providing a considerably wider range of ground shaking values 
than PSHA. In terms of efficiency in predicting ground shaking, measured accounting for the rate of underestimated events, the NDSHA maps appear to outscore the probabilistic ones.

\section{The neo-deterministic approach (NDSHA)}

The procedure for the neo-deterministic seismic zoning [2, 3] is based on the calculation of synthetic seismograms (earthquake scenarios). Starting from the available information on Earth structure, seismic sources, and the level of seismicity of the investigated area, it is possible to compute complete synthetic seismograms and the related estimates on peak ground acceleration (PGA), velocity $(\mathrm{PGV})$ and displacement (PGD) or any other parameter relevant to seismic engineering (such as design ground acceleration, DGA) which can be extracted from the computed theoretical signals. NDSHA defines the hazard from the envelope of the values of ground motion parameters determined considering a wide set of scenario earthquake; accordingly, the simplest product of this method is a map where the maximum of a given seismic parameter is associated to each site.

At regional scale, on account of the quality of the available data we discretize the study area with a $0.2^{\circ} \times 0.2^{\circ}$ regular grid. Each source in NDSHA at national scale is arbitrarily placed at the center of a cell of the grid; therefore we call it "cellular" source. Each cellular source is modeled as a scaled point-source and is characterized by focal mechanism and magnitude. Cellular sources are defined taking into account the available information, as provided by: the seismotectonic model, the morphostructural analysis and reported seismicity. Namely, the location of possible future earthquakes is constrained by the seismogenic zones and by the seismogenic nodes.

In the first step of cellular sources definition (discretization), earthquake epicenters reported in the catalogues (CPTI04 [8] for Italy, Zivcic et al. [9] for Slovenia and Markus et al. [10] for Croatia) are grouped into $0.2^{\circ} \times 0.2^{\circ}$ cells, and to each cell the maximum magnitude recorded within it is assigned. A smoothing procedure is then applied to account for spatial uncertainty and for source dimensions. The cellular sources that lie in a seismogenic zone (Meletti and Valensise [11]) are selected among the ones defined during the smoothing process and, if the resulting magnitude in each cell is lower than 5; a magnitude 5 is assigned by default. This choice is based on the hypothesis that, wherever a seismogenic zone is defined, damaging earthquakes may occur, and the value of 5 is conventionally (D'Amico et al. [12]) taken as the lower bound for the magnitude of damaging earthquakes.

In the framework of NDSHA, possible seismic sources are associated with the seismogenic nodes that are earthquake-prone areas identified through morphostructural analysis [13-15]. This choice allows us to consider potential strong earthquakes for areas where they are not yet observed, but which are recognized prone to strong earthquakes (Peresan et al. [16]).

A double-couple point source is placed at the center of each cell, with a focal mechanism consistent with the properties of the corresponding seismogenic zone 
or seismogenic node. The depth of the point-source is a function of the magnitude ( $10 \mathrm{~km}$ for $\mathrm{M}<7,15 \mathrm{~km}$ for $\mathrm{M} \geq 7$ ). Th is choice is consistent with the large errors generally affecting the hypocentral depth.

To define the physical properties of the source-site paths, the territory is divided into an appropriate number of polygons representing the average lithosphere properties at regional scale (Costa et al. [17]). Synthetic seismograms are computed by the modal summation technique for sites placed at the nodes of the grid that covers the national territory, considering the average structural model associated to the regional polygon that includes the site. The source-site distance is kept below a common upper threshold of $150 \mathrm{~km}$ for all the events. Seismograms are computed for an upper frequency content of $1 \mathrm{~Hz}$, which is consistent with the level of detail of the regional structural models, and the point sources are scaled for their dimensions using the spectral scaling laws proposed by Gusev [18], as reported in Aki [19]. DGA (Design Ground Acceleration) is the acceleration parameter computed by the standard NDSHA at national scale. This quantity is obtained by computing the response spectrum of each synthetic signal for periods of $1 \mathrm{~s}$ and longer (i.e. the periods present in the synthetic seismograms) and extending the spectrum, at frequencies higher than $1 \mathrm{~Hz}$, using a design response spectrum (for details see Panza et al. [2]).

Each site is thus associated with a number of seismograms corresponding to many different cellular sources. Since any parameter of interest can be extracted from such complete time series, different maps of seismic hazard that describe the ground motion at the bedrock can be produced. Among the parameters representative of strong ground motion we focus our attention on the widely used maximum ground acceleration, velocity, and displacement, but it is possible to consider integral quantities that can be of interest in earthquake engineering or engineering seismology $[20,21]$.

\section{NDSHA and earthquake's recurrence}

NDSHA defines the hazard as the maximum ground motion at the site, computed considering a large set of scenario earthquakes (including MCE), and, in its standard form, naturally and correctly, it does not supply information about the frequency of occurrence of the expected ground motion, since strong earthquakes are sporadic events. In fact, when an earthquake with a given magnitude $\mathrm{M}$ occurs, it causes a specific ground motion that certainly does not take into account whether the event is rare or not; thus ground motion parameters for seismic design should not be scaled depending on earthquake recurrence. Accordingly, in a cost-effective prevention perspective, when considering two sites prone to earthquakes with the same magnitude $\mathrm{M}$, given that all the remaining conditions are the same, the site where the recurrence is lower appears naturally preferable. Nevertheless parameters for seismic design must be equal at the two sites, since the magnitude we have to defend against is the same independently from the sporadicy of the earthquake.

Recurrence intervals play a role in decision making, and, contrary to PSHA, NDSHA can more adequately address earthquake recurrence because it can 
naturally separate ground shaking from related recurrence. In fact the standard procedure of NDSHA has been recently modified, allowing to take into account the additional information about earthquake recurrence (Magrin [22]). The standard map of ground motion is obtained along with the map of the corresponding recurrence, expressed as the number of times the ground motion is likely (on average) to be observed in a specified time window (e.g. 1000 years). The introduction of recurrence estimates in NDSHA naturally allows for the generation of ground motion maps for specified return periods that permits a straightforward comparison between the NDSHA and the PSHA maps.

In standard NDSHA cellular source and event coincide, because only the largest magnitude event is retained and modeled in each $0.2^{\circ} \times 0.2^{\circ}$ cell. In fact standard NDSHA only looks at the highest possible value of the ground motion predicted at the site via synthetic seismograms. This is fully sufficient to characterize the level of damage that the site may experience, but it does not allow the estimate of the recurrence of this damage. For the estimation of the recurrence of ground motion we must consider in each cellular source all the relevant events, whose magnitude is ranging between the maximum observed and magnitude 5.0 (the assumed lower cut-off of damaging earthquakes) and whose recurrence is estimated based on frequency-magnitude relation.

The recurrence estimation (estimate of frequency-magnitude relation parameters made within the polygons used to estimate of frequency-magnitude relation, from now recurrence polygons) is combined with the discretized observed seismicity. The characterization of the frequency-magnitude relation for earthquakes in the Italian region is performed by Kronrod [5] according to the multi-scale seismicity model (Molchan et al. [4]). The recurrence polygons are constructed merging zones of ZS9 seismotectonic zonation (Meletti and Valensise [11]).

Even if the seismogenic nodes are defined independently from the recorded seismicity (Alekseevskaya et al. [23]) and can fall in areas outside the recurrence polygons, which are defined on the base of recorded seismicity and ZS9 seismogenic zones, they can naturally contribute to the cellular sources in each recurrence polygon. In fact each node is a possible location for events not recorded in the catalog. As a rule it is not possible to associate a recurrence to the cellular sources that fall outside the available recurrence polygons, thus the recurrence parameters are not defined for Sicily and Grigioni-Valtellina zone because the data are not complete (Kronrod [5]).

Each computed seismogram represents the effect at a particular site (receiver) of the earthquake generated by one of the above-defined sources, so we can associate to each synthetic signal the recurrence of the event. At the site, all the incoming signals are sorted according to their peak ground motion value. In the standard NDSHA procedure, only the maximum value is considered, whereas for the estimate of recurrence a range of ground motion values must be taken into account. We choose to use the interval of peak ground motion values associated with each specific degree of macroseismic intensity (Panza et al. [2]). Accordingly, the total recurrence of events with intensity I is calculated as the sum of the recurrences associated to the single seismograms. If there is at least 
one event that produces a signal in the maximum ground motion range but that it is not characterized in terms of recurrence, the recurrence of maximum ground motion estimation is meaningless, so we don't provide this value. This situation is referred as "incomplete recurrence estimate" and the corresponding sites are marked by "?" in figure 1 that shows the map of maximum DGA and its recurrence. Obviously, the areas covered by "?" are the natural target for future investigations to be carried on with maximum priority.

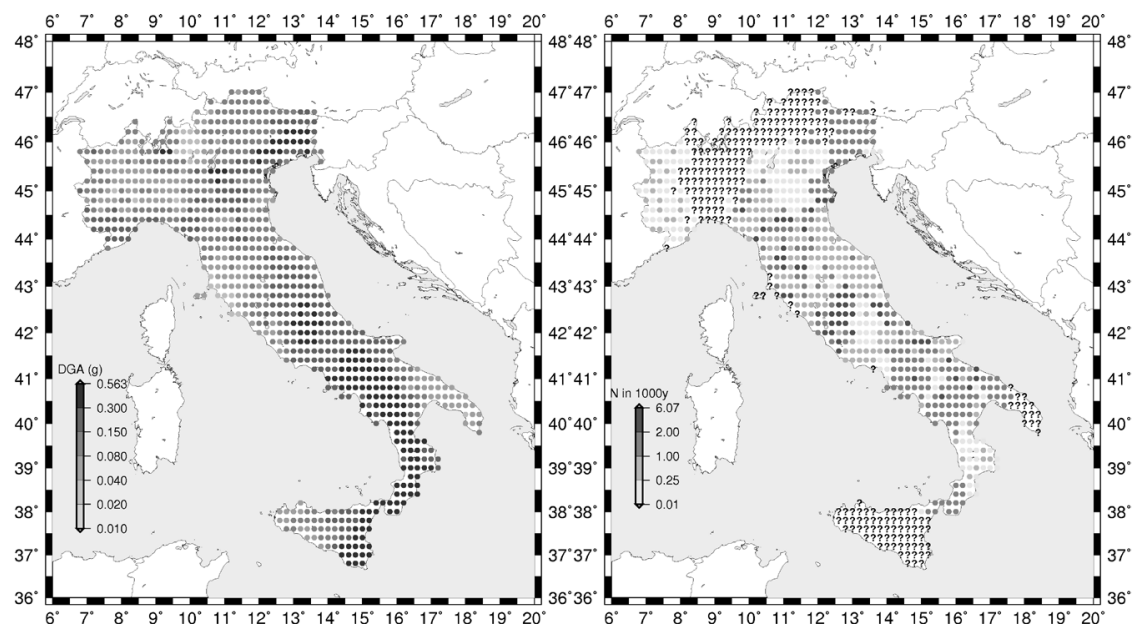

Figure 1: Map of maximum DGA (left) and its recurrence (right). Question marks represents sites with incomplete recurrence estimate of maximum ground motion, i.e. sites where recurrence of maximum ground motion cannot be reliably estimated.

\section{Comparison of the NDSHA and PSHA ground shaking maps for specified return periods}

The introduction of the recurrence in NDSHA provides the possibility to generate ground motion maps associated to a given return period. These maps provide the maximum ground motion level whose return period exceeds the specified value; accordingly the mapped ground motion is likely to occur at least once in a time interval that corresponds to the return period. Under the Poisson assumption, this procedure makes it possible to compute NDSHA maps of ground motion that can be directly compared with the PSHA estimates for a specific probability of exceedence.

Once selected the return period $\mathrm{T}$, all the signals associated to the site are sorted according to their peak ground motion value, from the highest to the lowest and their recurrence values multiplied by $\mathrm{T}$ (expected number of events in $\mathrm{T}$ years) are summed up. The summation of recurrence values terminates as soon as the value 1 event is reached or surpassed. The ground motion associated to the site is the one of the last term of the summation, i.e. corresponds to the lowest 
peak value. If in the summation for a site there is at least a signal produced by an event without estimation of recurrence, we exclude this site from the map of ground motion with fixed return period. This situation is referred in the following as "incomplete ground motion estimate for fixed return period" and those sites are marked by "?" in maps of ground motion with fixed return period (figure 2).

The maps obtained in the way just described do not supply the ground motion which will be experienced in T years, as the more severe (and rare) events could always happen within the time interval, therefore higher ground motion values may always occur.

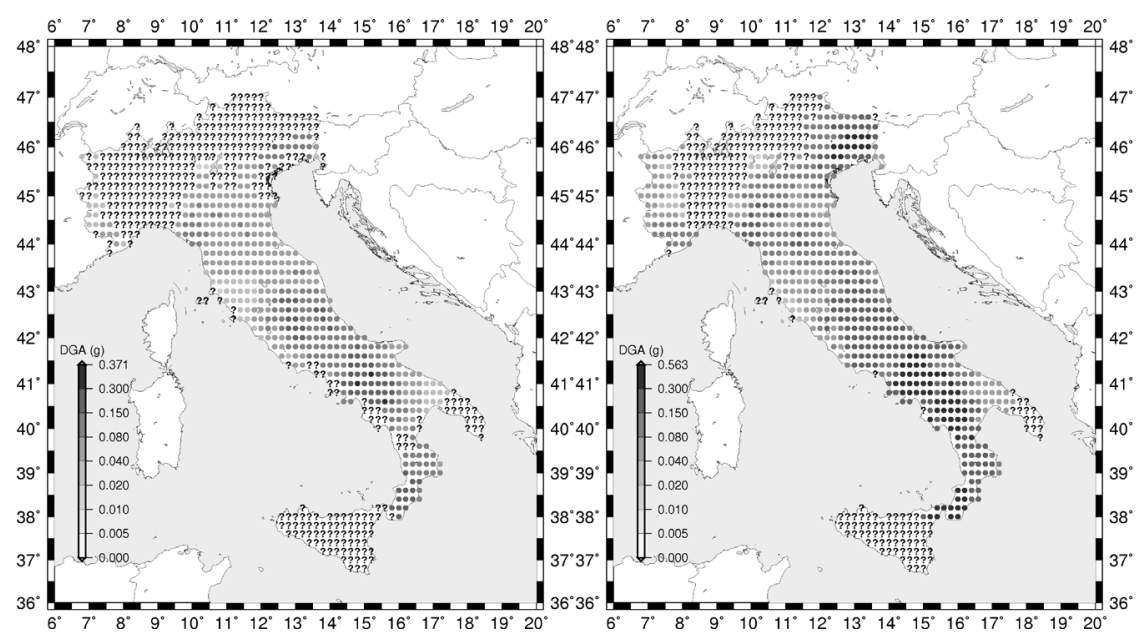

Figure 2: $\quad$ DGA determined with NDSHA for a return period $\mathrm{T}=475$ (left) and $\mathrm{T}=2475$ (right).

Before proceeding with the comparison between NDSHA and and PSHA maps with given return period, it is natural to analyze the two different NDSHA maps and the effect of recurrence on ground motion. We consider two return periods: 475 years which, for PSHA, is associated to a probability of exceedence of $10 \%$ in 50 years (the reference seismic hazard map for Italy) and 2475-year which, for PSHA, is associated to a probability of exceedence of PGA of $2 \%$ in 50 years. Remarkably, in the NDSHA map with return period of 475 years there are more sites with incomplete ground motion estimates than in that with $\mathrm{T}=2475$ years. In fact for the 475-year map we obviously must consider contributions from a larger number of signals than in the case $\mathrm{T}=2475$ years, and thus it is more likely that a signal produced by an event without estimation of recurrence is found. The diagrams in figure 3 point out that the choice of a fixed return period causes a systematic underestimation of the expected ground motion. By forecasting the expected value of shaking to be observed over a specified time interval, maps with fixed return period underestimate the actual shaking if earthquakes with longer recurrence times occur. 

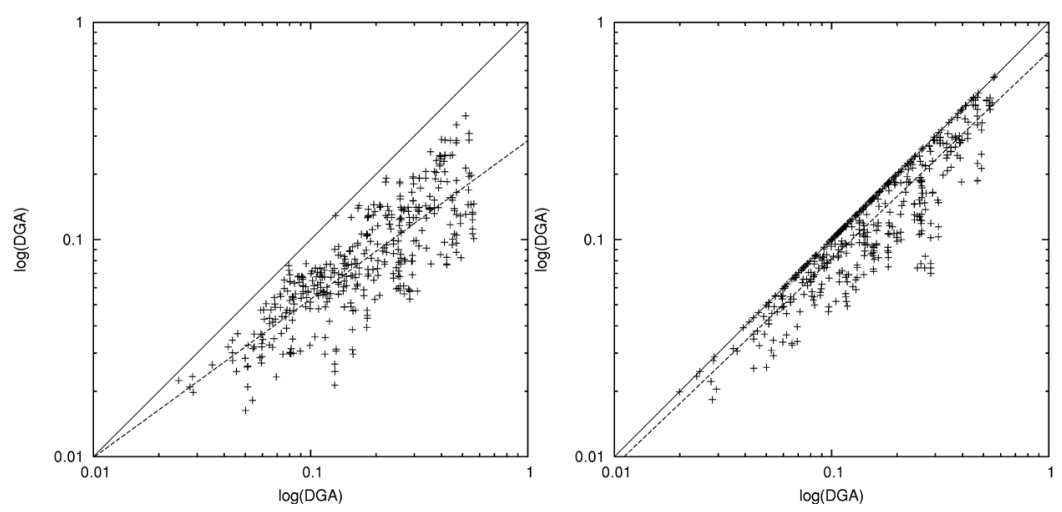

Figure 3: Diagram of DGA values determined with NDSHA for selected return periods ( $\mathrm{T}=475 \mathrm{left}, \mathrm{T}=2475$ right) (x axis) and the standard NDSHA DGA values (y axis).

To carry out the formal comparison between PSHA and NDSHA (Nekrasova et al. [6]), we consider the values of peak ground acceleration (PGA) in the seismic hazard maps for Italy, obtained by probabilistic seismic hazard assessment [22], sampled at the same grid points of the NDSHA map. The first comparison between NDSHA and PSHA maps is made for $\mathrm{T}=475$ years (PGA10\%). The PSHA values are generally higher. In Southern Italy, where strong earthquakes are more frequent, the results are quite comparable, whereas the greatest differences are in Central Italy and in the Po Valley. Another routinely available PSHA map for Italy is the one associated to the $2 \%$ probability of exceedence of PGA in 50 years (return period of 2475 years) (PGA2\%). Notably, the NDSHA values expected in Tuscany, a low-seismicity region, are three ranges lower than the ones predicted by PSHA. History has proven that Tuscany is a very low seismic area, and no seismogenic node has been identified within this region, but the PSHA map points out a relevant expected ground motion level. This may be a consequence of the tendency of the PSHA method to increase the seismic hazard in low-seismicity zones and it can be an evidence that PSHA is scientifically flawed: (1) as a complex computer model, it does not pass a simple sensitivity test with a single input earthquake: one earthquake could generate many ground motions at a site; (2) a mathematical error was committed in the original PSHA formulation (Cornell [25]) that led to equating the annual probability of exceedance (a dimensionless quantity) to the annual frequency or rate of exceedance (a dimensional quantity with unit of $1 / \mathrm{yr}$.). Even though the numbers are equivalent, 1 percent $(0.01)$ in one year is not equal to 1 percent $(0.01)$ per year because the dimensions are not equal. The reciprocal of 1 percent $(0.01)$ is 100 and means that the chance of occurrence is 1 in 100, not the average recurrence time in years (Wang and Cobb [26]). 


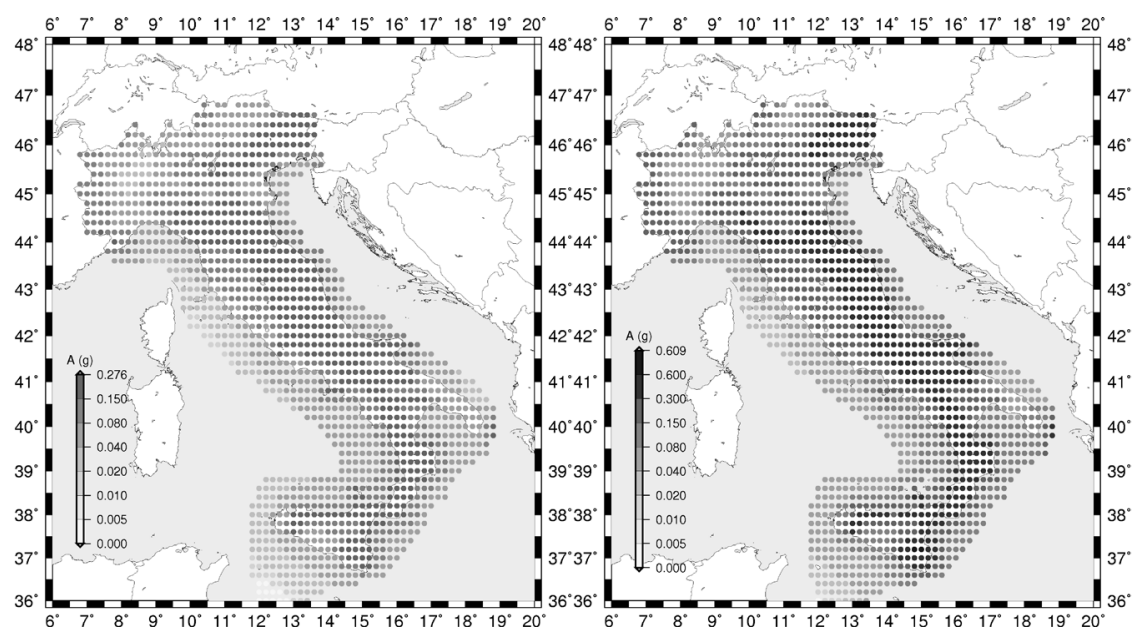

Figure 4: Probabilistic PGA for a return period $\mathrm{T}=475$ (left) and $\mathrm{T}=2475$ (right).

\section{Comparison of the NDSHA, PSHA seismic hazard maps and real seismicity for the Italian territory}

Rigorous and objective testing of seismic hazard assessments against the real seismic activity must become the necessary precondition for any responsible seismic risk estimation. As a case study, in Peresan and Panza [27] the predictions of NDSHA are compared to the PHSA ones for the Emilia earthquake area, as shown by maps published before the earthquake $[6,22]$. The PSHA map, forming the basis for the Italian building code, predicts PGA to be less than 0.175 times the acceleration of gravity $(\mathrm{g})$, whereas the NDSHA map predicts values in the range $0.20-0.35 \mathrm{~g}$, in good agreement with the observed motion that exceeded $0.25 \mathrm{~g}$. Comparison between PSHA and NDSHA estimates in terms of macroseismic intensity in Zuccolo et al. [7] indicates that the epicentral area of the Emilia earthquake is in a zone where PSHA predicted an intensity (as low as VIII on the modified Mercalli scale) at least one unit less than the NDSHA prediction, the latter of which is closer to the actual intensity of the earthquake.

A single case study obviously cannot be considered a rigorous testing of the two methods, therefore a more systematic test is performed in Nekrasova et al. [6]. The seismic hazard maps seek to predict the shaking that would actually occur, therefore the reference hazard maps for the Italian seismic code, obtained PSHA, and the ground motion maps based on NDSHA are tested against the real seismicity for the territory of Italy. The relations between the Intensity in the Mercalli, Cancani and Sieberg (MCS) scale and the ground acceleration values taken from Panza et al. [2] are used to convert the ground motion data from the different maps into the MCS scale values. To characterize the real seismic activity the information from the database of direct macroseismic observations 
DBMI04 (Stucchi et al. [28]) is used. Thus the predictions, as a rule, provide rather conservative estimates, except for PGA with $10 \%$ probability of being exceeded in 50 years, which underestimates the largest earthquakes.

Following the scheme proposed by Molchan [29], the efficiency in predicting ground shaking can be characterised by two types of errors. The first one is the percentage $\eta$ of failures to predict: $\eta=F / N$, where $F$ is the number of times the observed intensity I exceeds the predicted one and $\mathrm{N}$ is the number of reported events with intensity I. The second one is the percentage $\tau=\mathrm{A} / \mathrm{S}$, where $\mathrm{A}$ is the number of grid points which are assigned the intensity $I$ and $S$ is the total number of grid points. The strength of a prediction is estimated by the analysis of the "error diagram", collecting information on both types of errors. Since the random prediction gives $\eta+\tau=100 \%$ one can roughly estimate the quality of prediction by the deviation of $\eta+\tau$ from the corresponding $100 \%$ percentage. The sum of prediction errors obtained for the Italian territory is shown in table 1 . Accordingly, in terms of efficiency in predicting ground shaking, measured accounting for the rate of underestimated events and for the territorial extent of areas characterized by high seismic hazard (table 1), the NDSHA maps appear to outscore the PSHA ones.

Table 1: $\quad$ Sum of prediction errors for the three model maps compared to DBMI04 (taken from [5]).

\begin{tabular}{|c|c|c|c|}
\hline I & PGA10\% (\%) & PGA2\% (\%) & DGA (\%) \\
\hline XI & 100.00 & 33.75 & 28.06 \\
\hline X & 81.45 & 73.87 & 50.92 \\
\hline IX & 89.35 & 90.82 & 81.56 \\
\hline VIII & 102.58 & 100.07 & 98.14 \\
\hline
\end{tabular}

\section{Conclusions}

The comparison between the standard NDSHA map and the maps of ground motion for a given return period show that the introduction of a return period causes a systematic underestimation of the expected ground motion. The reference hazard maps for the Italian seismic code, obtained by PSHA, and the ground motion maps based on NDSHA are tested against the real seismicity for the territory of Italy. The comparison shows the predictions, as a rule, provide rather conservative estimates and that the NDSHA maps appear to outscore the PSHA ones in terms of efficiency in predicting ground shaking (table 1).

\section{References}

[1] Kossobokov, V.G., Nekrasova, A.K. Global Seismic Hazard Assessment Program Maps are Erroneous. Seismic Instruments 48 (2), p.p. 162-170, 2012. 
[2] Panza, G.F., Romanelli, F., \& Vaccari, F., Seismic wave propagation in laterally heterogeneous anelastic media: theory and applications to seismic zonation, Advances in geophysics, 43, pp. 1-95, 2001.

[3] Panza, G.F., Mura, C.L., Peresan, A., Romanelli, F., \& Vaccari, F., Seismic Hazard Scenarios as Preventive Tools for a Disaster Resilient Society. Advances in Geophysics, 53, 93-165, 2012.

[4] Molchan, G., Kronrod, T. \& Panza, G.F., Multi-scale seismicity model for seismic risk, Bulletin of the Seismological Society of America, 870(5), pp. 1220-1229, 1997.

[5] Kronrod, T., Estimation of $G-R$ law parameters for strong earthquakes in Italy, Technical report, ICTP, Miramare, Trieste, Italy, 2011.

[6] Nekrasova, A., Kossobokov, V.G., Peresan, A. \& Magrin, A., The comparison of the NDSHA, PSHA seismic hazard maps and real seismicity for the Italian territory, submitted to Natural Hazards.

[7] Zuccolo, E., Vaccari, F., Peresan, A. \& Panza, G.F., "Neo-deterministic and probabilistic seismic hazard assessments: a comparison over the Italian territory", Pure and Applied Geophysics, 168(1), pp. 69-83, 2011.

[8] Gruppo di lavoro, Catalogo parametrico dei terremoti italiani, versione 2004 (CPTI04), INGV, Bologna, http://emidius.mi.ingv.it/CPTI, 2004.

[9] Zivcic, M. Suhadolc, P. \& Vaccari, F., Seismic zoning of Slovenia based on deterministic hazard computations, Pure and Applied Geophysics, 157(12), pp. 171-184, 2000.

[10] Markus, S., Suhadolc, P., Herak, M. \& Vaccari F., A contribution to seismic hazard assessment in Croatia from deterministic modeling, Pure Appl. Geophys, 157, pp. 185-204, 2000.

[11] Meletti C. \& Valensise G., Zonazione sismogenetica ZS9 app.2 al rapporto conclusivo in redazione della mappa di pericolosità sismica prevista dall'ordinanza PCM 3274 del 20 marzo 2003. (ed. Gruppo di lavoro MPS), tech. rep., INGV, Milano - Roma, 2004.

[12] D’Amico, V., Albarello, D. \& Mantovani, E., A distribution-free analysis of magnitude-intensity relationships: an application to the Mediterranean region. Physics and Chemistry of the Earth, Part A: Solid Earth and Geodesy, 24(6), pp. 517-521, 1999.

[13] Gorshkov, A., Panza, G.F., Soloviev, A., \& Aoudia, A., Morphostructural zonation and preliminary recognition of seismogenic nodes around the Adria margin in peninsular Italy and Sicily, Journal of Seismology and Earthquake Engineering, 4(1), pp. 1-24, 2002.

[14] Gorshkov, A., Panza, G.F., Soloviev, A., \& Aoudia, A., Identification of seismogenic nodes in the alps and dinarides, Bollettino della Società geologica italiana, 123(1), pp. 3-18, 2004.

[15] Gorshkov, A., Panza, G.F., Soloviev, A., Aoudia, A., \& Peresan, A., Delineation of the geometry of nodes in the alps-dinarides hinge zone and recognition of seismogenic nodes, Terra Nova, 21(4), pp. 257-264, 2009.

[16] Peresan, A., Zuccolo, E., Vaccari, F., \& Panza, G.F., Neo-deterministic seismic hazard scenarios for north-eastern Italy, Bollettino della Società geologica italiana, 128(1), pp. 229-238, 2009. 
[17] Costa, G., Panza, G.F., Suhadolc, P., \& Vaccari. F., Zoning of the Italian territory in terms of expected peak ground acceleration derived from complete synthetic seismograms, Journal of applied geophysics, 30(1), pp. 149-160, 1993.

[18] Gusev, A., Descriptive statistical model of earthquake source radiation and its application to an estimation of short-period strong motion, Geophysical Journal of the Royal Astronomical Society, 74(3), pp. 787-808, 1983.

[19] Aki, K., Strong motion seismology, in Strong ground motion seismology (M. Erdik and M. Toksöz, eds.), 204 in NATO ASI Series, Series C: Mathematical and Physical Sciences, Springer, 1987.

[20] Decanini, L. and Mollaioli, F., Formulation of elastic earthquake input energy spectra, Earthquake engineering \& structural dynamics, 27(12), pp. 1503-1522, 1998.

[21] Uang, C. \& V. Bertero, V., Evaluation of seismic energy in structures, Earthquake Engineering \& Structural Dynamics, 19(1), pp. 77-90, 2006.

[22] Magrin, A. Multi-scale seismic hazard scenarios. PhD thesis, Univ. degli Studi di Trieste, 2012.

[23] Alekseevskaya, M., Gabrielov, A., Gel'fand, I., Gvishiani, A., \& Rantsman, E. Formal morphostructural zoning of mountain territories, Journal of geophysics, 43, pp. 227-233, 1977.

[24] Meletti, C. \& Montaldo, V., Stime di pericolosità sismica per diverse probabilità di superamento in 50 anni: Valori di a g, Progetto DPC-INGV S1, Deliverable D2, 2007.

[25] Cornell, C.A. Engineering seismic risk analysis. Bulletin of the Seismological Society of America, 58(5), pp. 1583-1606, 1968.

[26] Wang, Z. and Cobb, C., A critique of probabilistic versus deterministic seismic hazard analysis with special reference to the new Madrid seismic zone, Recent Advances in North American Paleoseismology and Neotectonics East of Rockies, 2012.

[27] Peresan A. \& Panza, G.F., Improving earthquake hazard assessment in Italy: an alternative to "Texas sharpshooting", EOS American Geophysical Union., 93(51), p. 538, 2012.

[28] Stucchi, M., Camassi, R., Rovida, A., Locati, M., Ercolani, E., Meletti, C., Migliavacca, P., Bernardini, F., Azzaro, R., DBMI04, il database delle osservazioni macrosismiche dei terremoti italiani utilizzate per la compilazione del catalogo parametrico CPTI04, Quaderni di Geofisica, 2007.

[29] Molchan, G.M., 1996. Earthquake prediction as a decision-making problem. Pure and Applied Geophysic. 147 (1), pp. 1-15. 